Research Article

\title{
Enhancement of Mechanical Properties on Novel Friction Stir Welded Al-Mg-Zn Alloy Joints Reinforced with Nano-SiC Particles
}

\author{
L. Natrayan $\left(\mathbb{D},{ }^{1}\right.$ M. Ravichandran $\mathbb{D}^{2},{ }^{2}$ Dhinakaran Veeman $\mathbb{D},{ }^{3}$ P. Sureshkumar $\mathbb{D},{ }^{4}$ \\ T. Jagadeesha, ${ }^{5}$ R. Suryanarayanan, ${ }^{6}$ and Wubishet Degife Mammo ${ }^{7}$ \\ ${ }^{1}$ Department of Mechanical Engineering, Saveetha School of Engineering, SIMATS, Tamil Nadu, Chennai 602105, India \\ ${ }^{2}$ Department of Mechanical Engineering, K. Ramakrishnan College of Engineering, Samayapuram, 621112, Tamil Nadu, India \\ ${ }^{3}$ Centre for Additive Manufacturing, Chennai Institute of Technology, Chennai, Tamil Nadu 600069, India \\ ${ }^{4}$ Department of Mechanical Engineering, Ramco Institute of Technology, Tamil Nadu, Virudhunagar 626125, India \\ ${ }^{5}$ Department of Mechanical Engineering, National Institute of Technology, Calicut, 673601 Kerala, India \\ ${ }^{6}$ School of Mechanical Engineering, Vellore Institute of Technology, Tamil Nadu, Chennai 600127, India \\ ${ }^{7}$ Mechanical Engineering Department, Wollo University, Kombolcha Institute of Technology, Kombolcha, South Wollo, \\ 208 Amhara, Ethiopia
}

Correspondence should be addressed to L. Natrayan; natrayanphd@gmail.com,

Dhinakaran Veeman; dhinakaranv@citchennai.net, and Wubishet Degife Mammo; wubishetdegife7@gmail.com

Received 27 July 2021; Revised 11 September 2021; Accepted 15 September 2021; Published 5 October 2021

Academic Editor: Lakshmipathy R

Copyright (c) 2021 L. Natrayan et al. This is an open access article distributed under the Creative Commons Attribution License, which permits unrestricted use, distribution, and reproduction in any medium, provided the original work is properly cited.

Friction stir welding (FSW) is a solid-state technique used to join Al-Zn-Mg alloys effectively compared with other conventional welding methods. Al-Zn-Mg alloy was processed for welding because they significantly demanded various engineering applications. A novel method of this research work is to characterize the unique mechanical properties of $\mathrm{Al}-\mathrm{Zn}-\mathrm{Mg}$ alloy reinforced with 1 to $3 \mathrm{wt} \%$ of nano silicon carbide (nano-SiC) particles developed by novel interlock friction-stir welding. The process parameters chosen for welding are rotational tool speed $1100 \mathrm{rpm}$, weld speed $25 \mathrm{~mm} / \mathrm{min}$, and triangular pin profile. The weld joint properties such as tensile strength, yield strength, and hardness were tested per ASTM standard. The microstructure of weld joints was studied with XRD and optical and scanning electron microscopy. The existence of silica particles in the weld joints and uniformed and homogeneous distribution of the particulates in the weld was verified by EDS analysis and microstructure. Al- $\mathrm{Zn}-\mathrm{Mg}$ reinforced with nano-SiC joints has better static properties due to intensive softening in the stir region. $\mathrm{Al}-\mathrm{Zn}-\mathrm{Mg}$ with $3 \mathrm{wt} \%$ nano-SiC exhibits maximum tensile strength, yield strength, and nugget hardness of $191 \mathrm{MPa}, 165 \mathrm{MPa}$, and $171 \mathrm{HV}$. Weld microstructures showed a pinning mechanism because nano-SiC particles were used as reinforcement during friction stir welding.

\section{Introduction}

Welding is the most widely used fabrication technique in the manufacturing industry. Friction stir welding (FSW) was invented by Thomas WM at TWI UK in 1991 to overcome the fusion welding problems [1]. Kapil and Sharma investigated on few similar and dissimilar materials and identified some unsolved critical issues [2]. Few researchers extend the limits of FSW in welding of different materials such as $\mathrm{Al}-\mathrm{Mg}$ [3], $\mathrm{Cu}-\mathrm{Al}$ [4], $\mathrm{Al}-\mathrm{Cu}$ [5], and plastics [6]. The material flow during the process was analytically studied [7]. Since its invention, the FSW process has been extensively used in various industrial applications, joining current and future advanced materials [8]. In this process, the shoulder/workpiece interface causes the frictional heat to form plastic deformation [9]. Welding parameters impact the material 
flow and heat generation, which affected the weld strength [10]. The surface roughness of the sample and the oxide layer presence were reported to influence the tensile shear force of the joint [11]. The rotational weld speeds of the tool and pin profile geometry affect the temperature and plastic flow field [12]. The filling stud is a single-stage process where the stud is placed onto the prefabricated hole in the joint. Weld joint strength was increased with an increase in TRS which was studied and reported in dissimilar AA7075-AA2024 Al-alloy FSW joints [13].

The weld quality was evaluated by the hardness of the joint; the relationship between peak temperature and hardness profile at the stir zone was investigated on AA6061AA7075 Al-alloy joints [14]. The impact of weld speed on joint strength was studied in dissimilar AA6061T6/AA7075-T6 Al-alloy joints. The welds were fabricated at different weld speeds of 80,100 , and $120 \mathrm{~mm} / \mathrm{min}$, where defect-free and superior strength joints were produced at $120 \mathrm{~mm} / \mathrm{min}$ [15]. Employing lower plunge depth during FSSW produced weaker mechanical interlocking. The gradual rise in the plunge depth produced a stronger FSSW joint. However, a variation in the hook morphology was observed [16]. The noncircular tool profiles were reported to allow a smoother flow of plasticized material around the pin by breaking the oxide particles and producing fine grains at the stir zone [17]. The effects of the number of passes on microstructure and mechanical properties were discussed and reported with an increasing number of pass, the average grain size in the weld zone of aluminium 5083 decreases, and mechanical properties increased [18]. The effect of TRS on the stir zone of dissimilar AA6061/AA7050 Al-alloy joints revealed that the degree of material transfer was influenced by the rotational tool speed [19]. The study report on AA6061/AA5086 Al-alloy revealed that welds fabricated with threaded cylindrical pin profiles exhibit better mechanical properties than welds fabricated with other welds [20]. Dissimilar AA6061/AA5010 Al-alloy welds made with square pin profile exhibit superior strength compared to cylindrical pin profiles [21]. The hardness at the TMAZHAZ was observed to be low compared to the other weld regions, irrespective of the changes in the process parameters. The detailed analysis of the weld zone by TEM revealed that the size and shape of the strengthening precipitate influence the microstructure and the microhardness. The adherence of the plasticized material on the pin at the high dwell times [22]. The study reported on dissimilar AA6061/AA2014 revealed that joints fabricated by hybrid square pin profiles exhibit good material flow than other welds [23]. The thread profiles were observed to influence the material flow in the FSW process [24]. The increased upward material flow was observed with the right-hand threaded tool, which resulted in the tunnel defect formation. However, with left-hand threaded tools, excellent tensile properties were obtained due to the increased downward material flow, which resulted in defect-free weld joints with superior tensile strength [25].

Fabrication of different grade materials with FSW is challenging to the researchers and manufacturers. FSW of $\mathrm{Al}-\mathrm{Mg}-\mathrm{Zn}$ alloys was reported to produce stronger weld
TABLE 1: Sample wt\% combinations.

\begin{tabular}{lc}
\hline Sample No. & \multicolumn{1}{c}{ Combinations } \\
\hline Sample 1 & Al-Mg-Zn/1.0 wt\% nano-SiC \\
Sample 2 & Al-Mg-Zn/1.5 wt\% nano-SiC \\
Sample 3 & Al-Mg-Zn/2.0 wt\% nano-SiC \\
Sample 4 & Al-Mg-Zn/2.5 wt\% nano-SiC \\
Sample 5 & Al-Mg-Zn/3.0 wt\% nano-SiC \\
\hline
\end{tabular}

joints than conventional fusion welding methods by inhibiting the negative influence of intermetallic compound formation due to high heat input. Therefore, the present study was aimed at investigating the influence of nano-SiC particle reinforcement on mechanical and microstructural properties of $2 \mathrm{~mm}$ thick dissimilar Al-Mg-Zn alloy FSW interlock weldments. Al-Mg-Zn alloy has been widely employed to fabricate truck frames, aircraft structures, automotive parts, marine and shipbuilding, storage tanks, railroad cars, etc.

\section{Experimental Procedure}

Flat plates of Al-Mg-Zn alloy of $2 \mathrm{~mm}$ thick with various $\mathrm{wt} \%$ of nanosilicon carbide particles (1 to $3 \mathrm{wt} \%$ ) with $10 \mathrm{~nm}$ particle size were added in joint lap configuration. Sample numbers with reinforcement $\mathrm{wt} \%$ are shown in Table 1 . Initially, the specimens were chemically treated to remove grease and dirt particles at the weld site. Then, the process is carried out by a friction stir welding machine [26].

The interlock FSW of Al-Mg-Zn alloy was conducted at $1100 \mathrm{RPM}, 25 \mathrm{~mm} / \mathrm{min}$ triangular pin and varying $\mathrm{wt} \%$ of nano-SiC particles from 1 to $3 \%$. The base metal of $100 \times$ $100 \times 2 \mathrm{~mm}$ thickness was milled to a depth of $1 \mathrm{~mm}$ and width of $35 \mathrm{~mm}$ along the longitudinal direction [27]. The aluminium sheet top surface was milled to $0.75 \mathrm{~mm}$ width, as shown in Figure 1. Nano-SiC reinforcements were filled in the top groove that intersects to produce a hybrid seal between the welds [28]. The nonconsumable tool material used for this experiment is AISI-H13 tool steel, shown in Figure 2. During the process, a shoulder diameter of $25 \mathrm{~mm}$ and a triangular profile pin of $3 \mathrm{~mm}$ inscribed in a circle of $8 \mathrm{~mm}$ diameter were employed [29]. The tool is plunged to a depth of $3 \mathrm{~mm}$ and traversed along the longitudinal direction to a distance of $85 \mathrm{~mm}$ to form a weld joint with assistance from frictional heat and plastic deformation [30].

FSW interlock weldments joined at varying wt $\%$ of nano-SiC samples are shown in Figure 3. The hardness was tested on a Vickers hardness testing machine with a working load of $110 \mathrm{kgf}$ and a dwell period of $10 \mathrm{sec}$ [31]. Tensile test was conducted as per ASTM E8 on the precision universal testing machine (SHIMADZU) which has a test load of $50 \mathrm{kN}$ at a crosshead velocity of $0.5 \mathrm{~mm} / \mathrm{min}$ [16]. Microstructure analysis was studied with optical scanning electron microscopy.

\section{Results and Discussion}

3.1. X-Ray Diffraction Test. Figure 4 shows the XRD pattern for FSW interlock samples in the heat-affected zone. The 


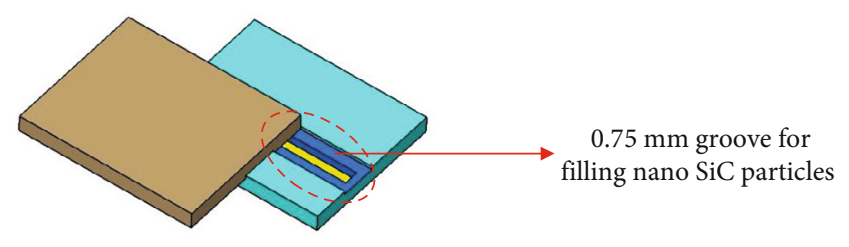

FIGURE 1: Groove in base metal.

weld cross section of the joint with the maximum tensile strength is analysed using XRD for different phases across the weld zone. In comparison to the normal diffraction data, the peaks were examined with the existence of various phases. $2 \theta$ reflections at $38.01,52.5$, and $75.6^{\circ}$ correspond to the $\mathrm{Al}$ phase [32]. $\mathrm{MgZn}_{2}$ and $\mathrm{MgSi}_{2}$ phase is confirmed from the peaks at 21.45 and 24.32 , respectively. The nano$\mathrm{SiC}$ particle peak was observed at 62.03 and $88.6^{\circ}$ confirmed with the JCPDS No. 29-1128. Peak intensity was found to vary with $\mathrm{Si}$ composition. It is observed that the peak shift was observed with increasing $\mathrm{Si}$ wt\%.

3.2. Temperature Measurement. During the FSW process, heat was generated from tool-workpiece interaction and the plastic deformation of the Al-Mg-Zn alloy. The temperature profile during the process was measured with the help of an infrared thermometer. The heat generated in the process is responsible for softening the material at the weld region, reducing the thermomechanical stresses on the tool during the process [33].

In the FSW process, the contact area between the pin profile and the weld surfaces was responsible for generating the frictional heat [34].

$$
\left.Q_{\mathrm{Tot}}=\frac{2 \pi \mu P \tau}{3} \omega\left(R^{3}-R_{\mathrm{p}}^{3}\right)+3 R_{\mathrm{p}}^{2} P_{1}\right)
$$

$Q_{T o t}$ is the total heat input, $\mathrm{W} ; \mu$ is the friction coefficient; $P$ is the axial force, $\mathrm{N} ; \omega$ is the rotational speed; $R$ is the shoulder radius, $\mathrm{m} ; R_{p}$ is the pin radius, $\mathrm{m}$; and $P_{l}$ is the pin length. The heat input was primarily estimated by using equation 1 as

$$
Q=\eta \frac{2 \pi \omega T}{V}
$$

The estimated heat generated of $9546.24 \mathrm{~W}$ during the process was calculated by using the following equation. The heat generated during the process was measured in terms of temperature with the help of an IR thermometer. The temperature transferred from NZ to the ends of the weld plates was observed to vary due to the influence of the tool shown in Figure 5. The maximum temperatures were observed during welding to be maximum around the edge of the tool.

3.3. Microstructure. The weldments were cut across the weld joint to view the microstructure. The specimens were prepared by polishing till a scratch-free mirror-like image was

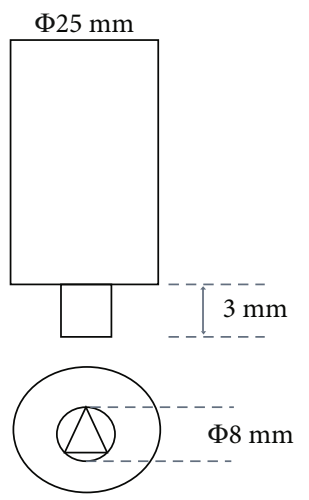

Figure 2: AISI-H13 tool steel dimensions.

obtained. Further, they are etched with Keller's reagent (95 $\mathrm{ml}$ of water, $2.5 \mathrm{ml}$ of nitric acid, $1.5 \mathrm{ml}$ of hydrofluoric acid, and $1 \mathrm{ml}$ of hydrochloric acid). The microstructures of etched specimens were observed under an optical microscope. The microstructures captured at different samples are shown in Figures 6(a)-6(d).

In the FSW process, the plastically deformed material in the weld zone was experienced by the thermomechanical cycle. The weld zone cross section has a fine-grained structure. In dissimilar material welding, the analysis of microstructure is complex due to the heterogeneous properties of materials. The microstructure obtained shows grains, grain boundaries are shown in Figures 6(a)-6(d) with intermetallic particles, and some grains are elongated. The microstructure analysis has reported that TMAZ consists of coarser and elongated grains because of the heat produced by the tool shoulder during rotation. Uniform distribution is observed in Figures 6(a)-6(d).

3.4. SEM Analysis. SEM image of the interlock friction stir welded sample with different w.t\% of nano-SiC is shown in Figures $7(\mathrm{a})-7(\mathrm{e})$. The microstructure at the weld zone was asymmetric due to different $w \mathrm{t} \%$ of the composition of the silicon carbide particles (Figures $7(\mathrm{a})$ and $7(\mathrm{~b})$ ). The elements magnesium and silicon form the $\mathrm{Mg}_{2} \mathrm{Si}$ compound shown as bright regions that do not dissolve in parent materials (Figures $7(\mathrm{c})$ and $7(\mathrm{~d})$ ). This leads to conclude that dark and bright lamellar originates from $\mathrm{Al}-\mathrm{Mg}-\mathrm{Zn}$ alloys. On the other hand, the welds processed with nano-SiC $3 \mathrm{wt} \%$ have uniform distribution and good mixing as shown in Figure 7(e).

EDAX analysis shown in Figures 8(a) and 8(b) addresses the secondary phase IMCs in the form of $\mathrm{Mg}_{2} \mathrm{Si}$, which 

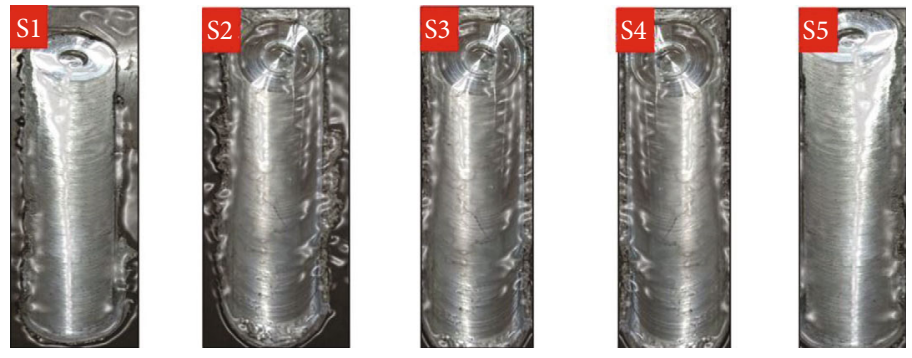

FIGURE 3: FSW interlock weldments joined at varying wt $\%$ of nano-SiC.

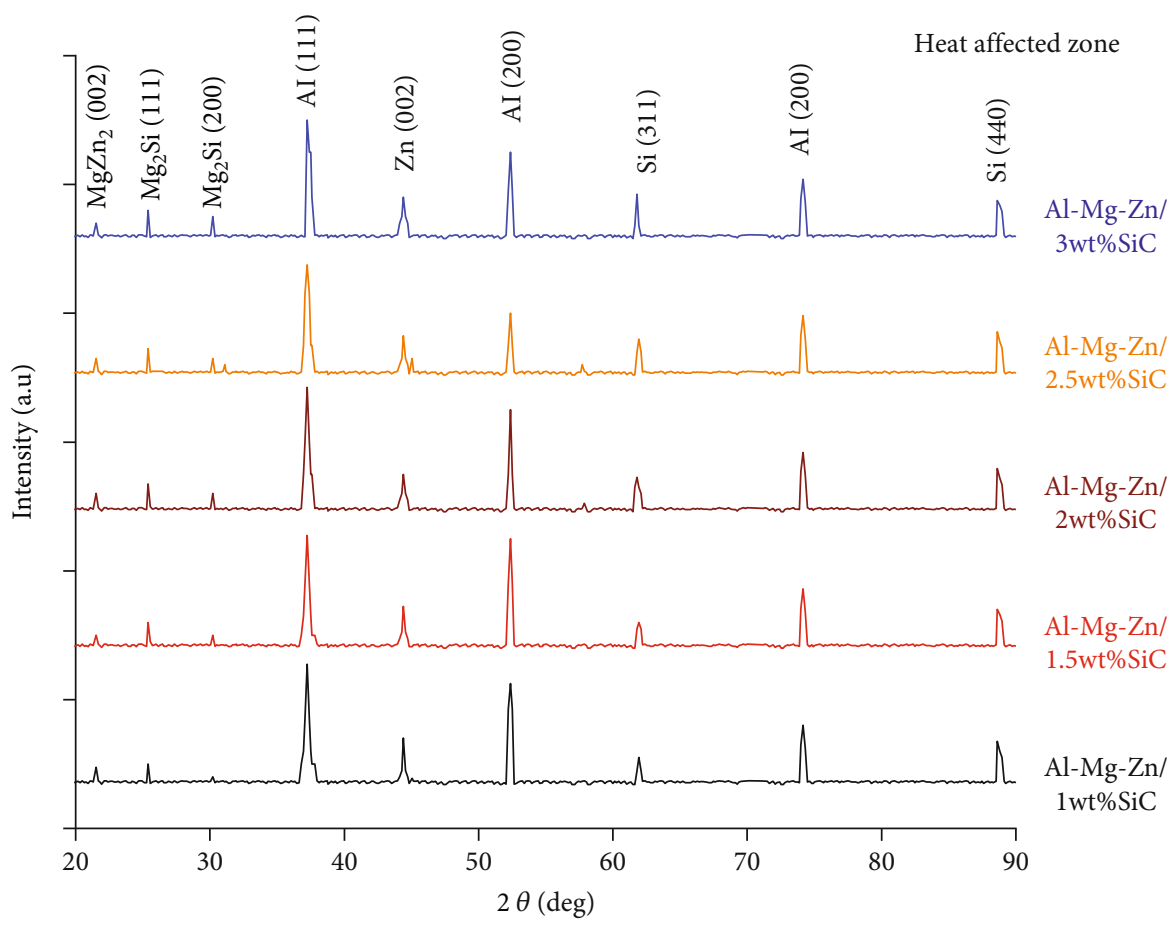

FIGURE 4: XRD pattern for FSW interlock samples (heat-affected zone).

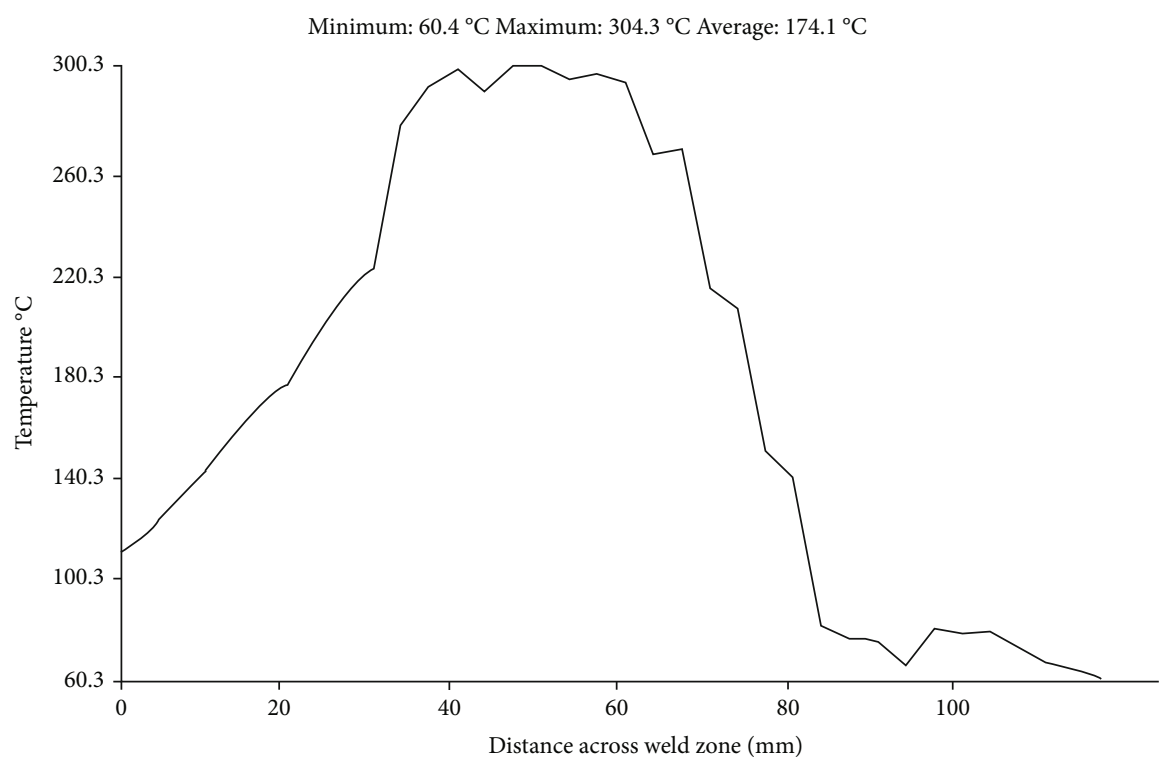

Figure 5: Temperature profile of weldment along the weld joint for sample 5. 


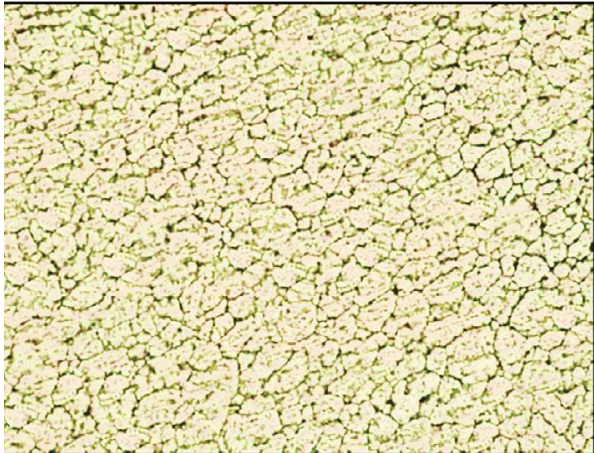

(a) $\mathrm{Al}-\mathrm{Mg}-\mathrm{Zn} / 1 \mathrm{wt} \%$ nano-SiC (sample 1)

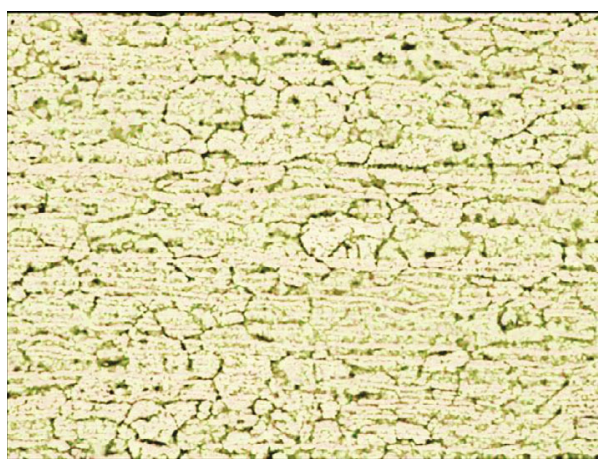

(c) Al-Mg-Zn/1 wt\% nano-SiC (sample 4)

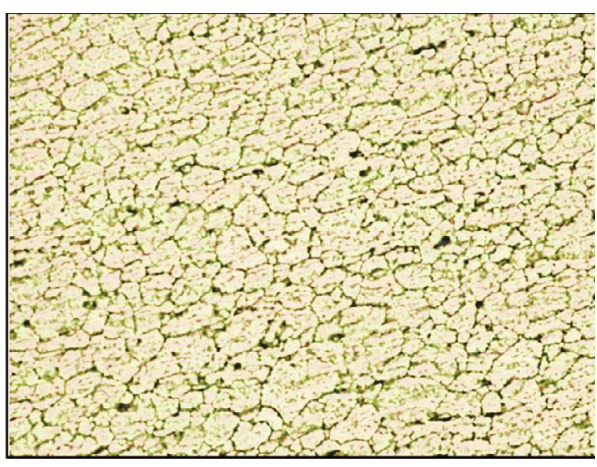

(b) Al-Mg-Zn/1.5 wt\% nano-SiC (sample 2)

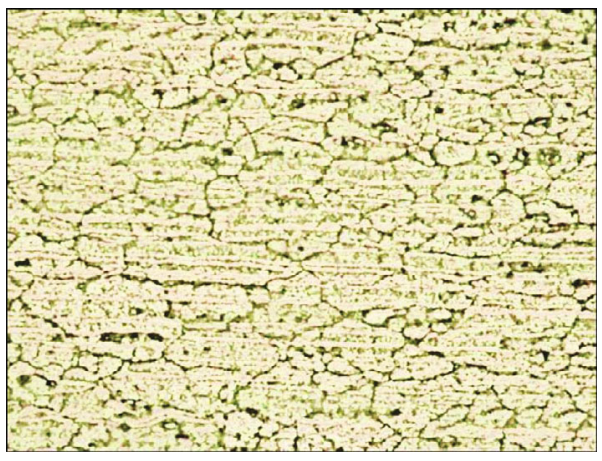

(d) Al-Mg-Zn/1 wt\% nano-SiC (sample 5)

FIGURE 6: (a-d) Microstructures of modified interlock FSW welded samples with addition of nano-SiC.

consists at the nugget zone. In the NZ, an average composition close to that of the Al-Mg-Zn was found in EDAX. The EDAX confirmed the elemental composition of the welds at the nugget zone. EDAX profile showed that $\mathrm{NZ}$ has less $\mathrm{Mg}$ content than base materials. The compounds like $\mathrm{Si}, \mathrm{Zn}, \mathrm{Mg}$, and $\mathrm{CO}_{3}$ were present in the NZ.

3.5. Mechanical Properties. The microstructure variations in and around the weld zone can lead to a change in the tensile strength of the weldment. FSW interlock sample mechanical properties and joint efficiency are shown in Table 2. Base metal strength was observed as $285 \mathrm{MPa}$. The joint efficiency is the ratio of UTS of the weld and UTS of the parent metal.

$$
\text { Joint efficiency } \%=\frac{\text { Weld joint strength }}{\text { Base metal strength }} \times 100 \text {. }
$$

3.6. Hardness. Hardness test was conducted on the transverse section of welded samples with a spacing of $5 \mathrm{~mm}$ and load of $110 \mathrm{kgf}$ with a dwell period of $10 \mathrm{sec}$. Al-Mg$\mathrm{Zn}$ with various wt $\%$ of nano-SiC samples interlocked with friction stir welding using triangular pin profiles processed at $1100 \mathrm{rpm}$ exhibits differences in hardness along the weld line as shown in Figure 9.

The hardness of the weld joint was determined across the weld zone. The hardness variation across the weld zone was observed to possess a $\mathrm{W}$ profile, with hardness at nugget higher than thermomechanically affected zone (TMAZ), heat-affected zone (HAZ), and parent metal irrespective of changes in wt\% of nano-SiC particles. The increased hardness at the nugget is credited to the grain refinement and nano-SiC particles. The intense stirring action during FSW and presence of nano-SiC particles resulted in severe plastic deformation resulting in increased hardness at the nugget. Moreover, nano-SiC particle addition resulted in grain boundary pinning [35]. The minimum hardness value was found at HAZ. The hardness at the HAZ is minimum due to precipitation phenomena [36]. The less hardness observed in the HAZ is due to the fact that IMCs may form $\mathrm{Mg}_{2} \mathrm{Si}$ and less $\mathrm{Si}$ compound on the Al-Mg-Zn/1 wt\% nano-SiC (sample 1). The maximum hardness values of sample 5 (Al-Mg$\mathrm{Zn} / 5 \mathrm{wt} \%$ nano-SiC) observed were 88 to $171 \mathrm{HV}$ from NZ to HAZ. The weld zone hardness varied between 125 and $171 \mathrm{HV}$.

3.7. Tensile Strength. Tensile test samples were prepared as per the standard of ASTM E8/ASTM B557. The test specimen shape was cut by wire EDM machine to get accurate dimensions shown in Figure 10. The test was conducted on the precision universal testing machine (SHIMADZU) at a test load of $50 \mathrm{kN}$ and a crosshead velocity of $0.5 \mathrm{~mm} / \mathrm{min}$. The results observed from the experiment are tabulated in Table 2. The test results revealed that the interlock welded joints failed by tensile and shear mode of failure.

The tensile and yield strength was observed to increase with the wt\% of nano-SiC particles. The increase in the 


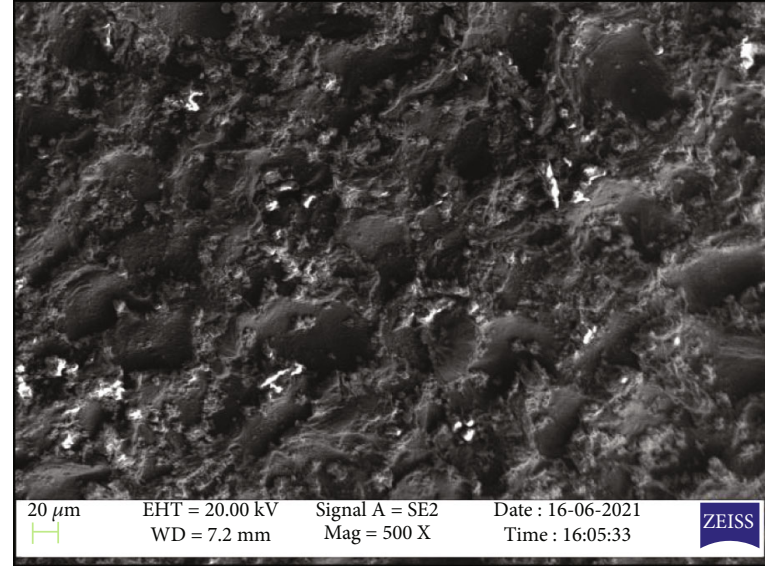

(a) SEM of Al-Mg-Zn/1 wt\% nano-SiC (sample 1)

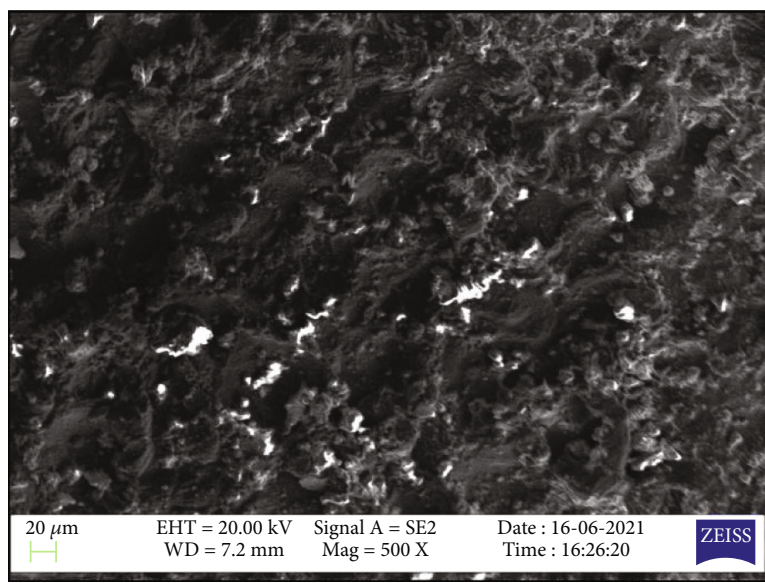

(c) SEM of Al-Mg-Zn/2 wt\% nano-SiC (sample 3)

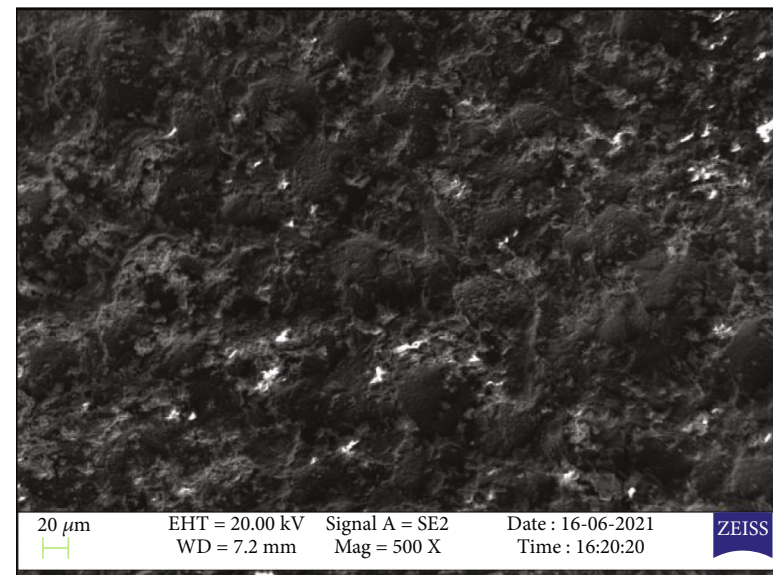

(b) SEM of Al-Mg-Zn/1.5 wt\% nano-SiC (sample 2)

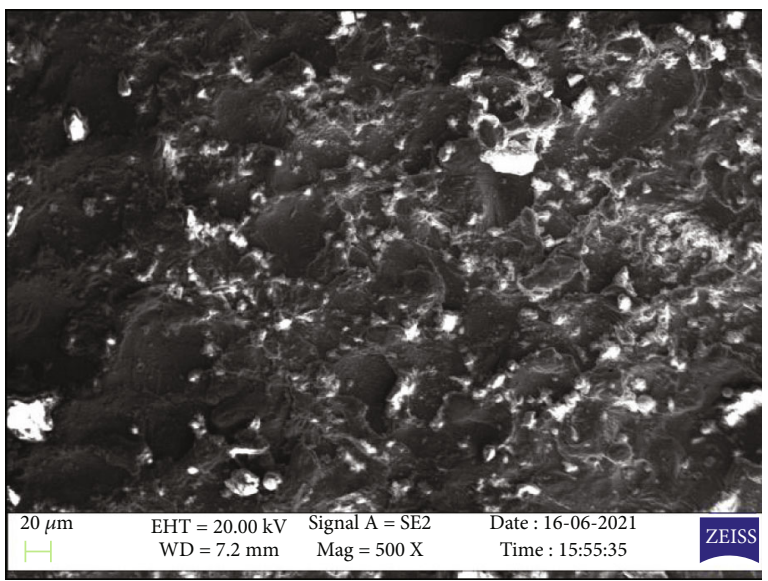

(d) SEM of Al-Mg-Zn/2.5 wt\% nano-SiC (sample 4)

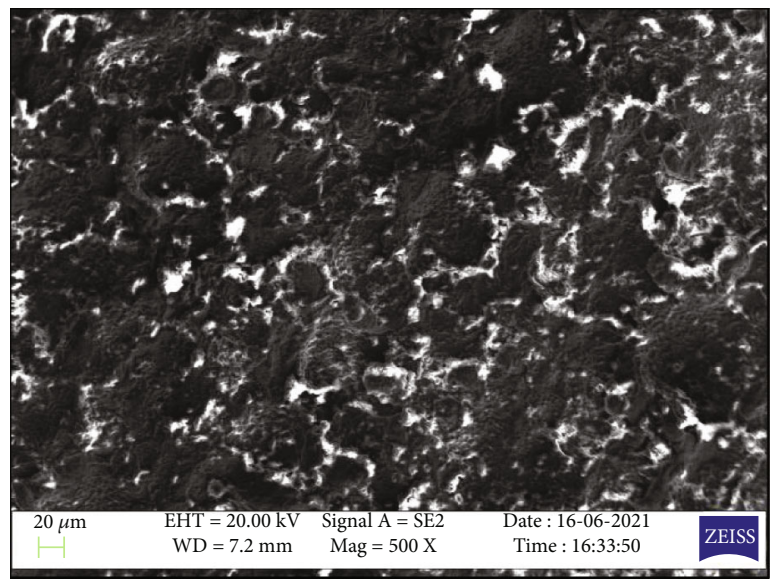

(e) SEM of Al-Mg-Zn/2.5 wt\% nano-SiC (sample 5)

FIGURE 7: (a-e) SEM images of modified interlock FSW welded samples with addition of nano-SiC.

mechanical strength of the weld joint with the increase in the $\mathrm{wt} \%$ of nano-SiC reinforcements is credited to the increased material mixing between the base metal and the reinforcement, which led to the accumulation of large amounts of reinforcement particles at the grain boundaries due to decreased dislocation during dynamic recrystallization [35].
The NZ was composed of equiaxed and fine grains, and TMAZ has coarse bent recovered grains. The fracture location is between WN and TMAZ on AS. Maximum UTS and YS values were recorded as $191 \mathrm{MPa}$ and $170 \mathrm{MPa}$, respectively. As per AWS D17 specifications, the joint efficiency factor for aerospace applications is 0.6 to 0.7 , 

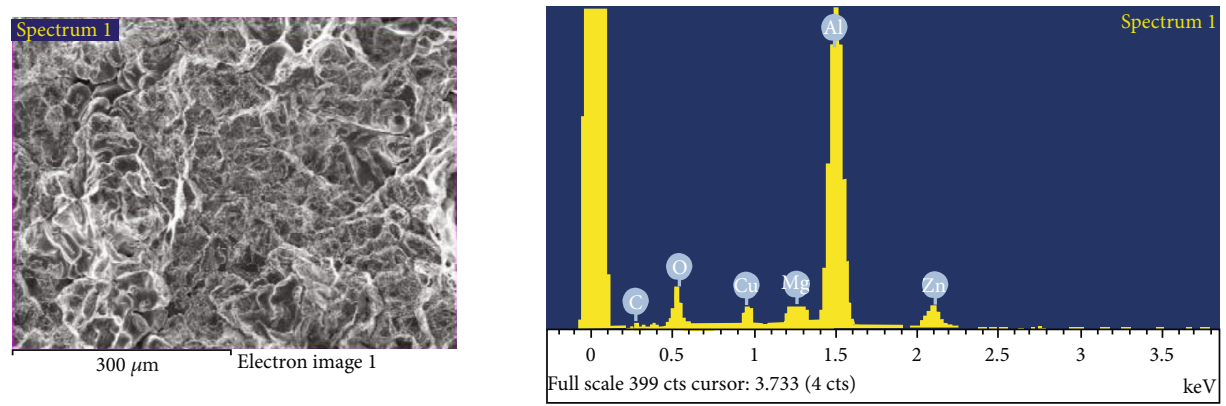

(a)
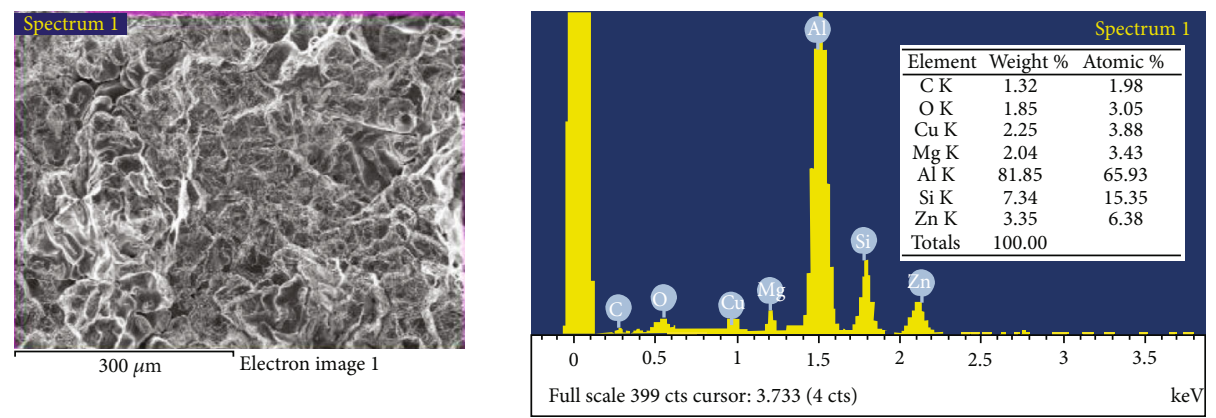

(b)

Figure 8: (a) EDAX analysis for Al-Mg-Zn/1 wt\% nano-SiC (sample 1). (b) EDAX analyses for Al-Mg-Zn/3 wt\% nano-SiC (sample 5).

TABLE 2: Mechanical properties of fabricated samples with joint efficiency.

\begin{tabular}{lcccc}
\hline Sample composition & Ultimate tensile strength $(\mathrm{MPa})$ & Hardness $(\mathrm{HV})$ & Yield strength $(\mathrm{MPa})$ & Joint efficiency $(\%)$ \\
\hline Al-Mg-Zn/1.0 wt\% nano-SiC & 125 & 137 & 94 & 0.43 \\
Al-Mg-Zn/1.5 wt\% nano-SiC & 143 & 152 & 99 & 0.50 \\
Al-Mg-Zn/2.0 wt\% nano-SiC & 157 & 163 & 107 & 0.55 \\
Al-Mg-Zn/2.5 wt\% nano-SiC & 178 & 167 & 133 & 0.62 \\
Al-Mg-Zn/3 wt\% nano-SiC & 191 & 171 & 165 & 0.67 \\
\hline
\end{tabular}

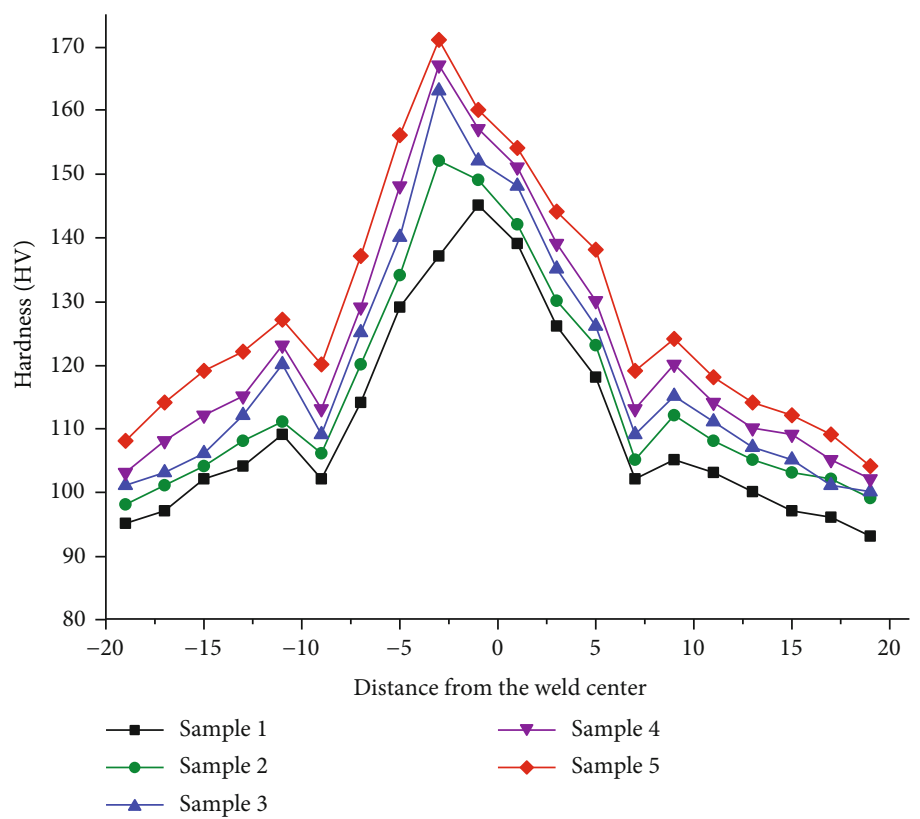

Figure 9: Hardness profile of weld joints processed at different wt\% of nano-SiC. 


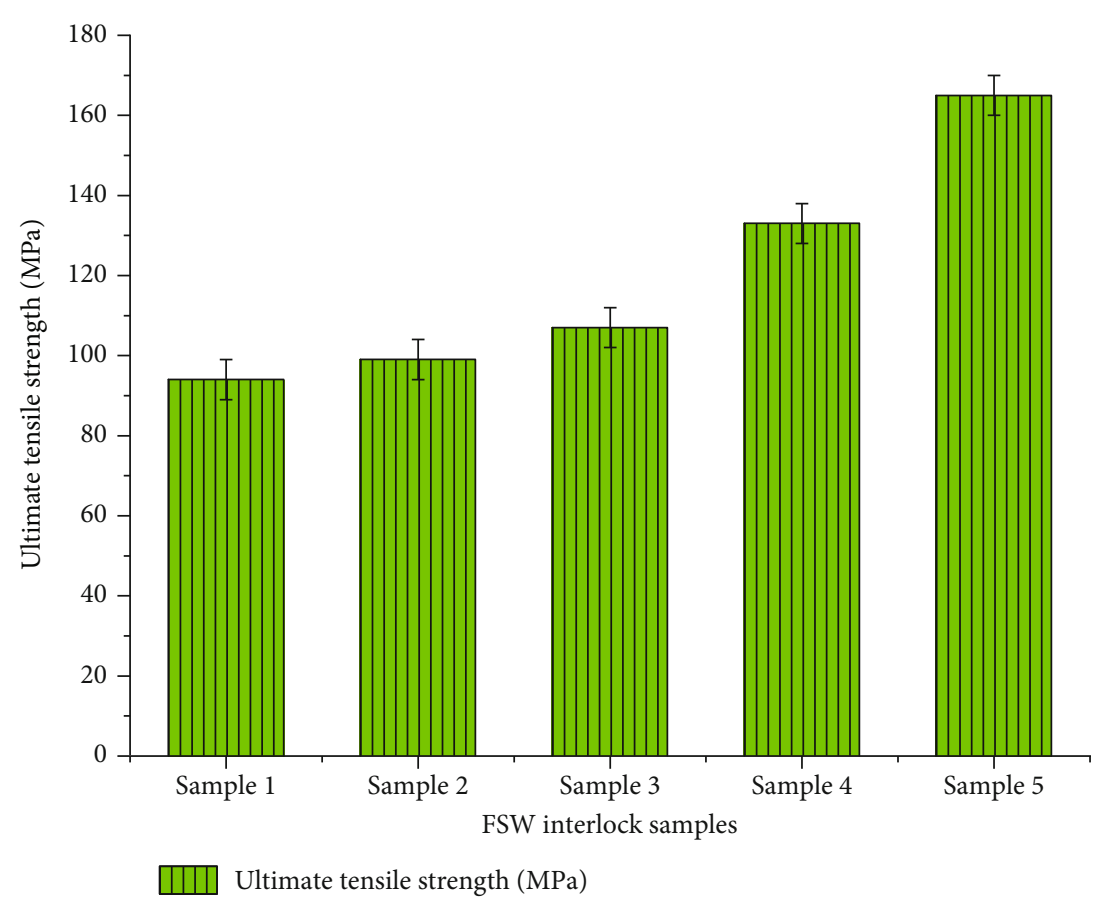

Figure 10: Tensile strength of weld joints processed at different wt $\%$ of nano-SiC.

achieved in this experiment sample 5. Hence, the fabricated joints were recommended for various structural applications where the above properties are required.

\section{Conclusions}

In this research, $\mathrm{Al}-\mathrm{Zn}-\mathrm{Mg}$ alloy added with 1 to $3 \mathrm{wt} \%$ of silicon carbide (nano-SiC) particles was successfully developed by novel interlock friction-stir welding methods. The process parameters chosen for welding are rotational tool speed $1100 \mathrm{rpm}$, weld speed $25 \mathrm{~mm} / \mathrm{min}$, and triangular pin profile. FSW interlock weld samples were characterized, and the following findings were drawn:

(i) $\mathrm{Al}-\mathrm{Zn}-\mathrm{Mg} / 3 \mathrm{wt} \%$ nano-SiC (sample 5) shows better yield strength, tensile strength, and hardness

(ii) SEM microstructure showed that very fine grains and nano-SiC particles uniformly mix between the base materials

(iii) EDAX analysis confirmed the presence of silicon carbide particles in the interlock weld zone

(iv) AWSD17 requirement attained with a common efficiency factor of 0.67

(v) The highest tensile strength was reported as $191 \mathrm{MPa}$, and hardness was reported as $171 \mathrm{HV}$

\section{Data Availability}

The data used to support the findings of this study are included in the article. Should further data or information be required, these are available from the corresponding author upon request.

\section{Disclosure}

This research was performed as a part of the Employment of Kombolcha Institute of Technology, Wollo University, Kombolcha, Amhara, Ethiopia.

\section{Conflicts of Interest}

The authors declare that there are no conflicts of interest regarding the publication of this paper.

\section{Acknowledgments}

The authors thank Saveetha School of Engineering, SIMATS, Chennai and Vellore Institute of Technology, Chennai, for providing characterization support to complete this research work.

\section{References}

[1] D. Kumar Rajak, D. D. Pagar, P. L. Menezes, and A. Eyvazian, "Friction-based welding processes: friction welding and friction stir welding," Journal of Adhesion Science and Technology, vol. 34, no. 24, pp. 2613-2637, 2020.

[2] A. Kapil and A. Sharma, "Magnetic pulse welding: an efficient and environmentally friendly multi- material joining technique," Journal of Cleaner Production, vol. 100, pp. 35-58, 2015.

[3] V. Firouzdor and S. Kou, "Al-to-Mg friction stir welding: effect of positions of $\mathrm{Al}$ and $\mathrm{Mg}$ with respect to the welding tool," Welding Journal, vol. 88, 2009. 
[4] X. Fei, Y. Ye, L. Jin, H. Wang, and S. Lv, "Special welding parameters study on $\mathrm{Cu} / \mathrm{Al}$ joint in laser-heated friction stir welding," Journal of Materials Processing Technology, vol. 256, pp. 160-171, 2018.

[5] C. W. Tan, Z. G. Jiang, L. Q. Li, Y. B. Chen, and X. Y. Chen, "Microstructural evolution and mechanical properties of dissimilar Al-Cu joints produced by friction stir welding," Materials and Design, vol. 51, pp. 466-473, 2013.

[6] R. Nandan, G. G. Roy, T. J. Lienert, and T. Debroy, "Numerical modelling of 3D plastic flow and heat transfer during friction stir welding of stainless steel," Science and Technology of Welding and Joining, vol. 11, no. 5, pp. 526-537, 2006.

[7] A. K. Kadian and P. Biswas, "Effect of tool pin profile on the material flow characteristics of AA6061," Journal of Manufacturing Processes, vol. 26, pp. 382-392, 2017.

[8] V. Paranthaman, K. Shanmuga Sundaram, and L. Natrayan, "Effect of silica content on mechanical and microstructure behaviour of resistance spot welded advanced automotive TRIP steels," SILICON, vol. 1, pp. 1-10, 2021.

[9] A. R. Darvazi and M. Iranmanesh, "Prediction of asymmetric transient temperature and longitudinal residual stress in friction stir welding of 304L stainless steel," Materials and Design, vol. 55, pp. 812-820, 2014.

[10] R. Suryanarayanan and V. G. Sridhar, "Effect of process parameters in pinless friction stir spot welding of Al 5754-Al 6061 alloys," Metallography, Microstructure, and Analysis, vol. 9, no. 2, pp. 261-272, 2020.

[11] S. Yogeshwaran, L. Natrayan, S. Rajaraman, S. Parthasarathi, and S. Nestro, "Experimental investigation on mechanical properties of Epoxy/graphene/fish scale and fermented spinach hybrid bio composite by hand lay-up technique," Materials Today: Proceedings, vol. 37, pp. 1578-1583, 2021.

[12] A. S. Avinash, "Evaluation on mechanical properties of basalt fiber-E glass reinforced polymer composite," Test Engineering and Management, vol. 83, pp. 14222-14227, 2020.

[13] C. Zhang, G. Huang, Y. Cao, Y. Zhu, and Q. Liu, "On the microstructure and mechanical properties of similar and dissimilar AA7075 and AA2024 friction stir welding joints: effect of rotational speed," Journal of Manufacturing Processes, vol. 37, pp. 470-487, 2019.

[14] S. Magesh, V. R. Niveditha, P. S. Rajakumar, S. Radha RamMohan, and L. Natrayan, "Pervasive computing in the context of COVID-19 prediction with AI-based algorithms," International Journal of Pervasive Computing and Communications, vol. 16, no. 5, pp. 477-487, 2020.

[15] J. F. Guo, H. C. Chen, C. N. Sun, G. Bi, Z. Sun, and J. Wei, "Friction stir welding of dissimilar materials between AA6061 and AA7075 Al alloys effects of process parameters," Materials and Design, vol. 56, pp. 185-192, 2014.

[16] L. Natrayan and M. Senthil Kumar, “An integrated artificial neural network and Taguchi approach to optimize the squeeze cast process parameters of $\mathrm{AA} 6061 / \mathrm{Al}_{2} \mathrm{O}_{3} / \mathrm{SiC} / \mathrm{Gr}$ hybrid composites prepared by novel encapsulation feeding technique," Materials Today Communications, vol. 25, p. 101586, 2020.

[17] K. Hemalatha, C. James, L. Natrayan, and V. Swamynadh, "Analysis of RCC T-beam and prestressed concrete box girder bridges super structure under different span conditions," Materials Today: Proceedings, vol. 37, pp. 1507-1516, 2021.

[18] D. Veeman, M. S. Sai, P. Sureshkumar et al., "Additive manufacturing of biopolymers for tissue engineering and regenerative medicine: an overview, potential applications, advancements, and trends," International Journal of Polymer Science, vol. 2021, Article ID 4907027, 20 pages, 2021.

[19] R. I. Rodriguez, J. B. Jordon, P. G. Allison, T. Rushing, and L. Garcia, "Microstructure and mechanical properties of dissimilar friction stir welding of 6061-to-7050 aluminum alloys," Materials and Design, vol. 83, pp. 60-65, 2015.

[20] M. Sandeep Kauthsa Sharma, S. Umadevi, Y. Sai Sampath et al., "Mechanical behavior of silica fume concrete filled with steel tubular composite column," Advances in Materials Science and Engineering, vol. 2021, 9 pages, 2021.

[21] M. Ahmadnia, S. Shahraki, and M. A. Kamarposhti, "Experimental studies on optimized mechanical properties while dissimilar joining AA6061 and AA5010 in a friction stir welding process," International Journal of Advanced Manufacturing Technology, vol. 87, no. 5-8, pp. 2337-2352, 2016.

[22] L. Natrayan and A. Merneedi, "Experimental investigation on wear behaviour of bio-waste reinforced fusion fiber composite laminate under various conditions," Materials Today: Proceedings, vol. 37, pp. 1486-1490, 2021.

[23] M. Raturi, A. Garg, and A. Bhattacharya, "Tensile strength and failure of dissimilar friction stir welded joints between 6061-T6 and 2014-T6 aluminum alloys," Procedia Structural Integrity, vol. 17, pp. 495-502, 2019.

[24] S. Yogeshwaran, L. Natrayan, G. Udhayakumar, G. Godwin, and L. Yuvaraj, "Effect of waste tyre particles reinforcement on mechanical properties of jute and abaca fiber- epoxy hybrid composites with pre-treatment," Materials Today: Proceedings, vol. 37, pp. 1377-1380, 2021.

[25] R. Suryanarayanan, V. G. Sridhar, L. Natrayan et al., "Improvement on mechanical properties of submerged friction stir joining of dissimilar tailor welded aluminum blanks," Advances in Materials Science and Engineering, vol. 2021, 6 pages, 2021.

[26] L. Natrayan and M. S. Kumar, "Optimization of tribological behaviour on squeeze cast al6061/al2o3/sic/gr hmmcs based on taguchi methodandartificial neural network," Journal of Advanced Research in Dynamical and Control Systems, vol. 11, no. 7, pp. 493-500, 2019.

[27] L. Natrayan, P. S. S. Sundaram, and J. Elumalai, "Analyzing the uterine physiological with MMG signals using SVM," International Journal of Pharmaceutical Research, vol. 11, no. 2, 2019.

[28] V. Paranthaman, K. S. Sundaram, and L. Natrayan, "Influence of $\mathrm{SiC}$ particles on mechanical and microstructural properties of modified interlock friction stir weld lap joint for automotive grade aluminium alloy," SILICON, vol. 1, pp. 1-11, 2021.

[29] V. V. Patel, V. J. Badheka, and A. Kumar, "Influence of pin profile on the tool plunge stage in friction stir processing of $\mathrm{Al}-\mathrm{Zn}-\mathrm{Mg}-\mathrm{Cu}$ alloy," Transactions of the Indian Institute of Metals, vol. 70, no. 4, pp. 1151-1158, 2017.

[30] L. Natrayan and M. Senthil Kumar, "A novel feeding technique in squeeze casting to improve reinforcement mixing ratio," Materials Today: Proceedings, vol. 46, pp. 1335-1340, 2021.

[31] G. Ghangas and S. Singhal, "Effect of tool pin profile and dimensions on mechanical properties and microstructure of friction stir welded armor alloy," International Journal of Pharmaceutical Research, vol. 5, no. 6, 2018.

[32] C. S. S. Anupama, L. Natrayan, E. Laxmi Lydia et al., "Deep learning with backtracking search optimization based skin lesion diagnosis model," Computers, Materials \& Continua, vol. 70, no. 1, pp. 1297-1313, 2022. 
[33] H. I. Dawood, K. S. Mohammed, A. Rahmat, and M. B. Uday, "Effect of small tool pin profiles on microstructures and mechanical properties of 6061 aluminum alloy by friction stir welding," Transactions of Nonferrous Metals Society of China, vol. 25, no. 9, pp. 2856-2865, 2015.

[34] H. Search, C. Journals, A. Contact, M. Iopscience, M. Simul, and I. P. Address, "A local model for the thermomechanical conditions in friction stir welding," Modelling and Simulation in Materials Science and Engineering, vol. 13, no. 1, pp. 77-93, 2005.

[35] H. A. Deore, J. Mishra, A. G. Rao, H. Mehtani, and V. D. Hiwarkar, "Effect of filler material and post process ageing treatment on microstructure, mechanical properties and wear behaviour of friction stir processed AA 7075 surface composites," Surface and Coatings Technology, vol. 374, pp. 52-64, 2019.

[36] R. Suryanarayanan and V. G. Sridhar, "Process parameter optimisation in pinless friction stir spot welding of dissimilar aluminium alloys using multi-start algorithm," Proceedings of the Institution of Mechanical Engineers, Part C: Journal of Mechanical Engineering Science, vol. 234, no. 20, pp. 41014115, 2020. 